\title{
AC 2008-1005: EXPOSING CHEMICAL ENGINEERING STUDENTS TO REAL WORLD PROBLEMS: HEALTH CARE AND RENEWABLE ENERGY SYSTEMS
}

\section{Nichole Au, University of Maryland-Baltimore County}

Ms. Au is a 2008 Magna Cum Laude graduate with a BS degree in Chemical Engineering (Bioengineering Track) with a minor in History. She is also an Honors College graduate and a member of Tau Beta Pi. She has been working on the INSPIRES curriculum for the last year and will continue this work as she completes her MS degree in Chemical \& Biochemical Engineering in spring 2009.

\section{Taryn Bayles, University of Maryland-Baltimore County}

Taryn Bayles is a Professor of the Practice of Chemical Engineering in the Chemical and Biochemical Engineering Department at UMBC, where she incorporates her industrial experience by bringing practical examples and interactive learning to help students understand fundamental engineering principles. Her current research focuses on engineering education, outreach and curriculum development.

\section{Julia Ross, University of Maryland-Baltimore County}

Julia Ross is Professor and Chair of the Chemical and Biochemical Engineering Department at the University of Maryland, Baltimore County. Her technical research interests are in the area of cellular engineering. In particular, her work focuses on bacterial adhesion to physiological surfaces. In addition, she maintains an active research program in curriculum development with a focus on workforce development. She is also the 2007 recipient of the ASEE Sharon Keillor Award for Women in Engineering Education. 


\title{
Exposing Chemical Engineering Students to Real World Problems: Heath Care and Renewable Energy Systems
}

\begin{abstract}
High school and entry level engineering students seldom have a good understanding of the types of problems that chemical engineers solve. Two design projects have been developed to introduce high school and entry level engineering students to real world problems related to health care and energy systems. We have found that through these design projects our students begin to understand the breadth of chemical engineering.
\end{abstract}

For our Engineering in Health Care design project, students are introduced to a patient suffering from kidney disease, who explains her experience with dialysis in a professional produced video segment. The students then go through a number of hands-on activities, demonstrations and computer simulation where they learn about the factors that influence dialysis. The patient and her doctor then challenge the students to design, build and test a hemodialysis system. The hemodialysis system must remove a minimum amount of 'impurities' from simulated blood, while minimizing both the cost of the dialysate (water) and the hemodialysis system. The teams subsequently evaluate the performance of the prototype that they create.

The second design project, Engineering Energy Solutions, focuses on the world's energy crisis. As the world moves further into the $21^{\text {st }}$ century, the need for development in the field of renewable energy is becoming more apparent. The amount of fossil fuels available continues to decline and statistics show that only one barrel of oil is discovered for every six that are utilized. In fact, if the current rate of consumption is maintained, worldwide oil reserves are slated to last only for the next forty years. Therefore it is essential that renewable energy technology must continue to grow. The next generation of students represents those engineers who will struggle with energy issues over the ensuing century. In our Engineering Energy Solutions design project, students are asked to design, construct, test, and evaluate a system for collecting, storing, transporting, converting, and utilizing renewable energy from a water, wind, or solar source. The overall goal of the project is to light a 1 cell AAA Maglite ${ }^{\circledR}$ light bulb after being allowed to collect energy for 45 minutes and up to two hours.

As part of the INSPIRES (INcreasing Student Participation, Interest and Recruitment in $\boldsymbol{E}$ ngineering and $\boldsymbol{S}$ cience) Curriculum (funded by the NSF), the design projects have been tested with a wide range of students who include: high school pre-engineering students, freshmen engineering students and sophomore and junior chemical engineering students. In conjunction with the design projects a series of hands-on activities and mini design challenges have been developed to enhance the understanding of the fundamental principles related to the design challenge. A web based tutorial features interactive animations and design simulations that allow students to adjust parameters to investigate the effect that each has on the efficiency of their simulated design. In addition, an on-line tutorial features pre and post assessments on content knowledge of the design process and underlying concepts. The results of these assessments will be compiled and presented; as well as details of the design projects and their solutions. 


\section{Background}

Most undergraduate chemical engineering programs face the challenge of continually evolving a traditional curriculum to meet the demands of the $21^{\text {st }}$ Century. This very idea was presented to ASEE in 1994 in "Engineering Education for a Changing World," and it remains as valid today as fourteen years ago.

"Engineering education programs must be relevant, attractive and connected:

- Relevant to the lives and careers of students, preparing them for a broad range of careers, as well as for lifelong learning involving both formal programs and hands-on experiences;

- Attractive so that the excitement and intellectual content of engineering will attract highly talented students with a wider variety of backgrounds and career interests-particularly women, under-represented minorities and the disabled — and will empower them to succeed; and

$\circ$ Connected to the needs and issues of the broader community through integrated activities with other parts of the educational system, industry and government." 1

Chemical engineering programs nationwide continue to struggle with the challenges of the changing world. Attracting students to engineering begins with sparking interest in young minds. Programs like INSPIRES are meant to appeal to the nation's youth and get them to consider the possibility of engineering as a future career. Early exposure to the innumerable possibilities and opportunities open to engineers as far as occupation and field of choice may provide the incentive necessary to attract more students to engineering. For the two modules being presented, Engineering in Health Care and Engineering Energy Solutions, the INSPIRES program partnered with experts from both academia and industry to develop both the content of the web-based tutorials and the design challenges.

Freshmen college students often enter chemical engineering without a clear picture of what the major entails, let alone what they will do with a chemical engineering degree after graduation. One of the goals of the INSPIRES curriculum is to present the fact that engineers, and chemical engineers in particular, often enter a wide variety of fields. The Engineering in Health Care and Engineering Energy Solutions INSPIRES modules reflect real-world problems that chemical engineers face today, and the students are given the theory and background information needed to consider possible solutions. The curriculum guides students through the engineering design process, which includes hands-on activities and mini design challenges coupled with the webbased tutorials and interactive simulations, to lead them to the final design challenge. The Engineering in Health Care module has been tested with a wide range of students, and the Engineering Energy Solutions module is slated to begin testing in 2008.

\section{Engineering in Health Care: A Hemodialysis Case Study}

The Engineering in Health Care module has proven to be compelling for students participating in the INSPIRES curriculum. The students are introduced to hemodialysis through a professionally 
produced video segment presenting a teenage patient affected by kidney disease and her doctor. This real-world situation involves the students in the process of trying to help a real person with a life-threatening disease. The Engineering in Health Care module explains to the students the theory and basic principles behind hemodialysis, so that they are prepared to test their knowledge in the final design challenge.

\section{Hands-On Activities}

The INSPIRES curriculum incorporates several hands-on activities that are either used as small group activities or class demonstrations. For example, to demonstrate the concept of diffusion an air freshener is sprayed from one corner of the room and students are asked to raise their hands when they detect the scent. In a demonstration directly related to the final design challenge, a sample of the simulated blood is placed in a dialysis membrane and placed in a cup of water. The students watch the dialysate (water) turn yellow from the "impurities" (tartrazine) that pass through the membrane. In order to visualize the effect of temperature on diffusion, the students have a cup of hot water and a cup of cold water side-by-side. At the same time, a drop of food coloring is added to each, and the students are able to observe the food coloring diffusing more quickly in the hot water. The last hands-on activity is designed to have the students understand how volumetric flow rate of water draining from a funnel depends on the height difference between the height of the funnel and outlet tube opening. The Bernoulli equation is introduced to have students predict the exit flow rates, and compare them to measured flow rates. This activity helps them with their final hemodialysis system design in which both the simulated blood and dialysate must flow.

\section{Pre and Post-Design Challenges}

Both the pre and post-design challenges are intended to introduce the design process and assess the capabilities of the students before and after the INSPIRES curriculum. "In Search of Snap, Krackle and Pop!!" is the pre-design challenge. The students work in small groups to design a device to separate Rice Krispies $®$ cereal from a mixture of seven different cereal types. The intent of this mini design challenge is to introduce to the students the idea of being able to separate a mixture based on size of the components as an analogy for the membrane pore-size separation of the hemodialysis final design challenge.

The post-design challenge, "Separate This," also has the students create up to four separation processes to remove colored sand from a mixture of sand, corn starch, salt, rice, glitter, metal filings, and metal BB's. This challenge incorporates the idea that multiple physical properties can be exploited in separation processes. The challenge also assesses the students' abilities to use the design process to successfully work in groups to design and build a safe, functional project.

\section{Final Design Challenge}

The overall design challenge for the Engineering in Health Care module is to design and construct a device that simulates a hemodialysis system. The goal is to maximize the removal of impurities from simulated blood while using a minimum amount of dialysate (water) and 
minimizing the total cost of the system. In an interactive computer simulation, the students manipulate various parameters to affect the efficiency of a simulated design. There are four choices of membrane, varied in pore size and the tubing diameter (which are the same parameters that the students will select from for their hemodialysis system design), and a range of flow rates for the blood and dialysate. The simulation provides practice for the actual design project. From the simulation, the students should have a good idea of how these parameters affect the efficiency of the dialysis, and they need to balance this with the major design factor, which is cost.

A traditional membrane separation process has a fluid with component(s) that need to be removed, and a membrane that can selectively remove those components, which pass through to a carrier fluid. In the design challenge, the students are given 0.5-L of simulated unfiltered blood that contains impurities that need to be removed. In groups, they choose a membrane and then design and build an apparatus to support it. The simulated blood flows through the membrane tubing, and the impurities (tartrazine) passes through the membrane to the dialysate (water) on the other side. The students can then assess the efficiency of their hemodialysis system. Based on the color of the final dialysate, the students compare their sample to the known concentration standard to determine their concentration of "impurity," which is then used to calculate the amount of "impurity" removed. The "bragging rights" for their entire project is then determined by using the following metric:

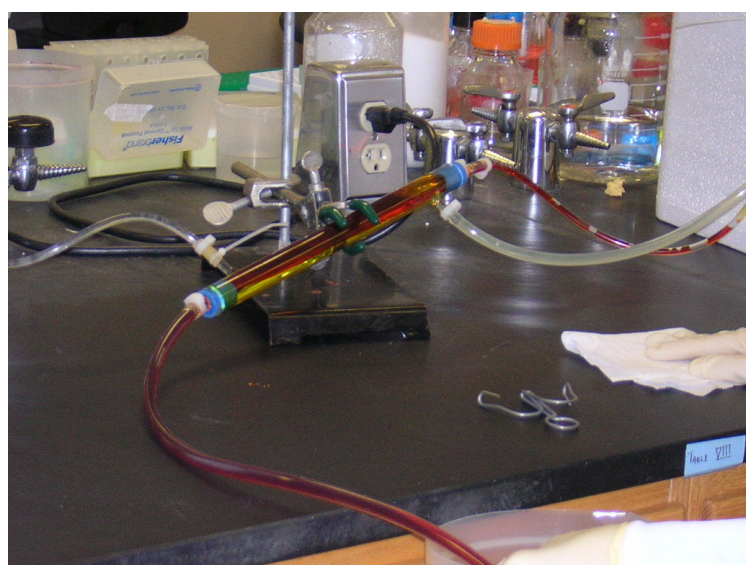

\section{Removal of impurities (in mg) $x$ dialysate cost index $x$ device cost index}

The dialysate is valued at $\$ 20.00$ per liter and the cost index is calculated using:

Minimum dialysate cost of a hemodialysis system that meets the design requirements Team dialysate cost

The device cost index is calculated using:

\section{Minimum TOTAL design cost of a hemodialysis system that meets the design requirements Team TOTAL design cost}

Every design is unique, but the majority of successful designs are at least structured similarly. A length of membrane tubing is placed within a larger-diameter tube. The simulated blood flows through the membrane through one set of tubes and the water dialysate flows inside the larger tube and outside the membrane, flowing in and out through another set of tubes. The result is a flow of filtered simulated blood and a dialysate that has removed tartrazine from the blood. Most groups manipulate variables like the membrane diameter and pore size (from the four choices provided), materials, co- versus countercurrent flow, and flow rates in order to achieve the most efficient and effective separation with the least cost possible. The maximum cost of 
device is $\$ 50$ and the dialysate costs $\$ 20$ per liter. Groups have to minimize cost by minimizing both the use of materials, including membrane, and dialysate.

One particular group designed an innovative apparatus that placed three smaller membrane tubes inside a larger membrane tube, which was inside a Tygon ${ }^{\circledR}$ tube, so that the simulated blood that flowed in the annular space outside the three smaller membranes and inside of the larger membrane. The dialysate flowed inside the three smaller membranes and also in the annular space of the Tygon ${ }^{\circledR}$ tube. They achieved a very high percentage of tartrazine removal and successfully compensated for a relatively higher total cost for their device.
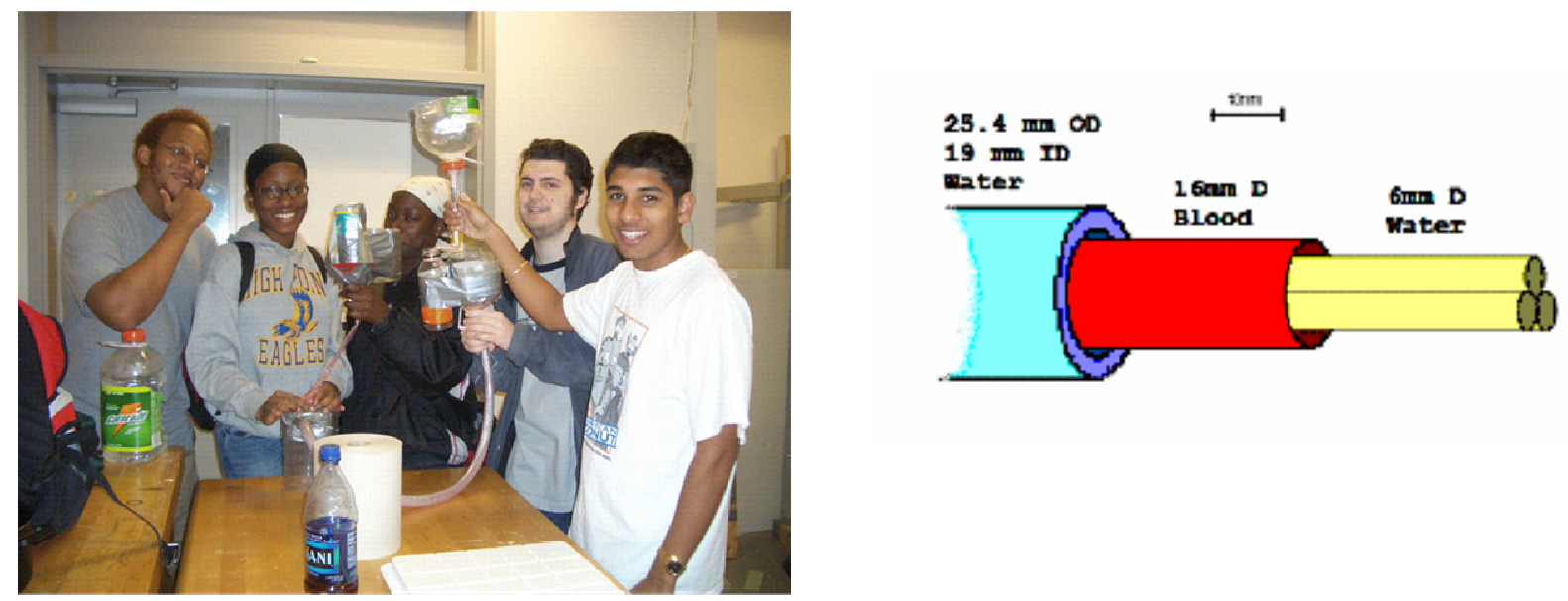

The final design challenge connects all the aspects of the Engineering in Health Care module, including the engineering design process. The theory from the introductory lectures and the web-based tutorial about the variables that affect this membrane separation can be applied to a hands-on design project. Students also have the opportunity to use the interactive computer simulation to manipulate variables for a simulated design and choose the best combination of variables, including membrane diameter and pore size, flow rates of blood and dialysate, and coor counter-current flow. After testing their theories on the computer, the students apply their knowledge to design and construct their apparatus. They go through the design process, from defining the problem and conducting research to brainstorming possible solutions and simulating the designs to actually building the prototype and testing it. After going through the design process, the students are brought back to the real-world significance of their efforts, trying to help the patient affected by kidney disease.

\section{Engineering Energy Solutions: A Renewable Energy Systems Case Study}

In the Engineering Energy Solutions module, students consider a completely different field where chemical engineers face a different set of challenges. Engineering Energy Solutions addresses an equally compelling issue: the world energy crisis. Through lectures and the webbased tutorial, students are exposed to the situation that engineers face today about our consumption of non-renewable energy resources and the complications of implementing renewable energy systems. Students are introduced to the idea that challenges in engineering energy solutions are not solely at the collection stage, but are the result of the inefficiencies and 
difficulties encountered in every step of an energy system from collection to storage, to transport, and to consumption. Most people do not recognize that although it is important to discover and develop alternative sources of energy, it may be even more important to improve upon both current and future technologies for more efficient use of those sources. The Engineering Energy Solutions module addresses both of these issues and teaches students the engineering principles and design skills required for them to understand and tackle them.

\section{Hands-On Activities}

One of the goals of the Engineering Energy Solutions module is to help students grasp the concept of energy and the sheer amount of energy that is required to operate everyday devices. One of the hands-on activities is specifically designed for that purpose. A hand-cranked generator is used to light two different light bulbs: an incandescent light bulb and a light-emitting diode (LED). Students use their cranking power to discover how much energy it takes to light up each bulb. In a related hands-on activity, students build a "shaker flashlight" to illuminate a LED from the kinetic energy from passing magnets inside a coil to convert it into electrical energy. The students are given the opportunity to demonstrate just how much energy it takes to operate those modern conveniences they take for granted. A challenge that engineers face in the energy field is developing an energy system that allows the energy collected to be converted into a form of useful work. The other hands-on activities address this challenge, with the intention of getting students to think beyond energy collection. The "Let it Blow!" activity instructs students to construct a small windmill; kinetic energy from the wind can be used to turn blades on a wind turbine and converts the energy into electrical energy which can be measured using a voltmeter or used to light up an LED. In "All Geared Up," students construct a K'Nex gear system to hold a weight attached to a pulley. Depending on the gear ratios, the potential energy transferred from the falling weight to the gears affects the speed of the gears used to pull up a weight on the other side. This demonstrates to students the effect that efficiency has on even a simple system. For "Beam Me Up with Solar Power," the students construct a system with a solar panel attached to a motor. Solar energy can be converted to electrical energy using the solar panel. The electrical energy can be used to power a motor which is used to rotate a pulley, which in turn

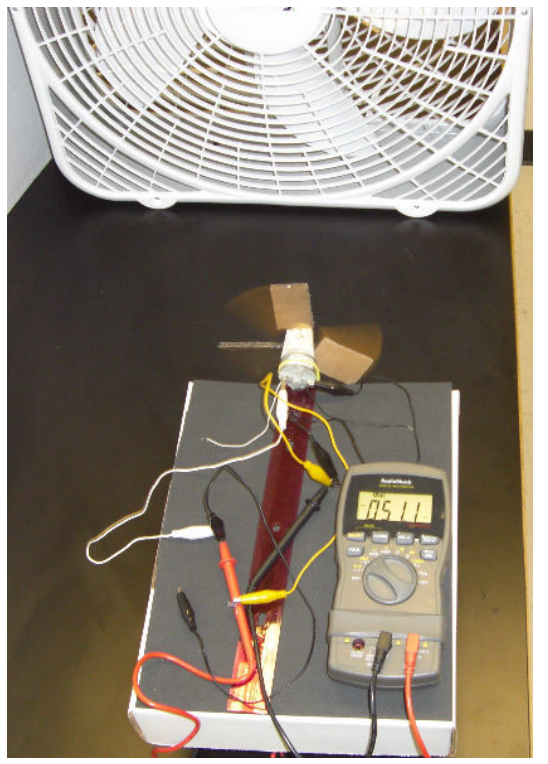
can lift a small weight.

\section{Pre and Post-Design Challenges}

Many energy-related activities designed for students often neglect to convey to students the idea that the challenge for engineers in the energy field is not limited to finding alternative energy sources. By improving the efficiencies of energy conversion, storage, and transfer, the energy that is harnessed can be better utilized, and the end result is more energy available for consumption. The intention of the hands-on activities and the pre and post-design challenges is 
to introduce to the students that energy solutions could be at any step of an energy system, from collection to consumption.

In "Power It Up!" the students work in groups to design and construct a waterwheel using very basic materials: index cards, masking tape, fishing line, a dowel rod, and a 2-liter soda bottle with holes drilled in each end. Each group is given two quarts of water to spin their waterwheels. The waterwheel is attached to a weight on a string, and the kinetic energy from the spinning waterwheel lifts the weight. The group's performance is gauged by the amount of power produced, which is affected by the distance the weight was lifted and the time it took to lift it.

The post-design challenge, "Power It Up with Gears!" is similar to the pre-design challenge because the students construct a waterwheel, but this time the waterwheel must be connected to a geared device which is used to lift the weight. The materials for construction are K'Nex building parts, small cups, masking tape, and fishing line. Each K'Nex gear, pulley, connector, and rod is given a cost. The goal is not only to lift the weight in the shortest amount of time, but also to minimize the total device cost.

\section{Final Design Challenge}

The overall design challenge for this module is to design and build a system that collects energy from a renewable source (solar, hydro, or wind), converts the energy into a form that can be transported, stores it for a specified period of time, and then uses the energy to illuminate a light bulb. The goal is to optimize the efficiency of the system, simply put, to maximize the ratio of the useful work output to the energy input. The fact that this project forces the students to look at an entire system, as opposed to only a single part, makes it somewhat unique. From the engineering design standpoint, it makes the students think not only about how each parameter and principle affects the end goal, but also about how the different principles and parameters relate to and affect one another.

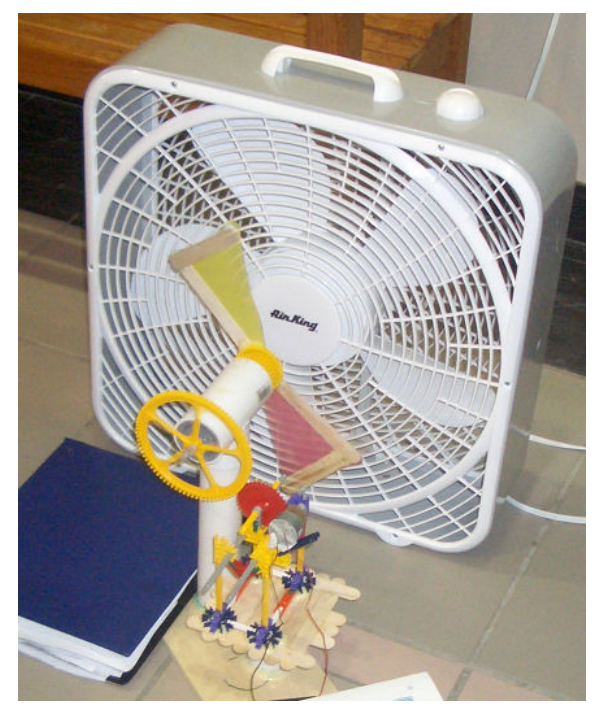

The students have 45 minutes (or up to two hours) in which to collect energy from one of the sources, and that energy must somehow be stored, converted, and transferred to light a 1-cell AAA Maglite® light bulb. The renewable energy sources provided are a 90-W light bulb for solar, a box fan $(166,117$, or 87 Watts) for wind, or a water stream that flows at 0.5 liters/second for hydro. The device must cost less than $\$ 75$, including the collection, storage, transfer, and conversion pieces.

\section{Power Generated $x$ Overall System Efficiency $x$ Device Cost Index}

The power generated refers solely to the ability of the system to light the light bulb, not to any power being generated elsewhere in the system. The power generated is determined by the maximum current that your device can produce as measured using a meter. 
The overall system efficiency is calculated using:

\section{Useful Work Output \\ Energy Input}

The energy input is determined from the renewable energy source used (the wattage $\mathrm{x}$ time collected), and the useful work output is determined from the energy emitted from the light (wattage $\mathrm{x}$ time lit).

The device cost index is calculated using:

Minimum TOTAL design cost of an energy system that meets the design requirements Team TOTAL design cost

The energy design project has been tested in both the high school and university environments: the Young Engineers and Scientists Seminar (YESS) high school outreach program and the freshman Introduction to Engineering course (ENES 101). ${ }^{2,3}$ Teams have successfully used wind, solar and hydro energy systems, and no one energy source performed the best each time. The design must collect from a renewable energy source, convert the energy into a form that can be transported, store the energy for a specific period of time, and then use the energy to illuminate a light bulb. The majority of students collect from solar, wind, or hydro sources, but the various collection devices are incredibly unique. Most groups that use wind and hydro sources also use a motor-turbine to convert the kinetic energy, and the majority of all groups use rechargeable batteries to store the energy. However, every group has a unique project, and the energy system aspect of the project allows groups additional freedom.

Students prove incredibly innovative when approaching this design challenge, and while some groups can only light the bulb for the minimum required 15 seconds, others are able to light the bulb for hours. Some groups spend the maximum $\$ 75$ on their design, while others are successful with a minimal cost. As part of the design process, these students learn how to choose the best solution based on all of these considerations. The concept of the design process is carried throughout all the INSPIRES modules, and Engineering Energy Solutions and Engineering in Health Care modules are two examples of less-traditional design challenges presented.

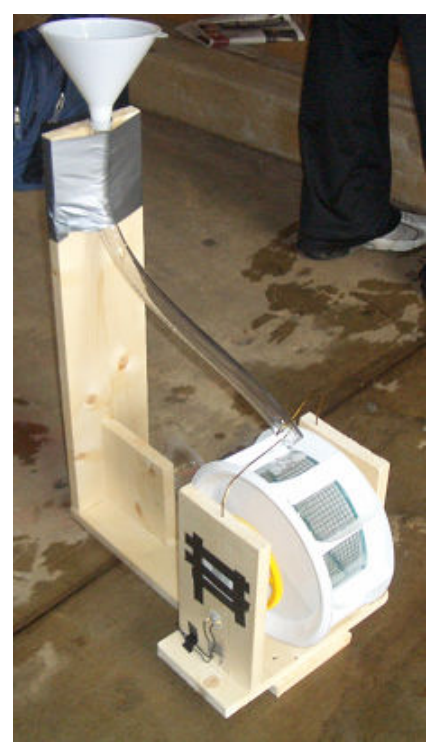

\section{Results and Discussion}

Many of the high school teachers that have tested the INSPIRES curriculum have expressed a great interest in adapting the Engineering in Health Care module for permanent use in preengineering curricula. Some have also expressed a desire to have INSPIRES modules in the biology or medical area because they feel there is a lack of curricula or material in these areas for 
high school pre-engineering. Many students find the Engineering in Health Care module unique, and the hemodialysis design challenge attracts a great number of students in the YESS Program. Often, the students in the INSPIRES program remark on the compelling story of the patient with kidney disease that gives their learning and the design challenge societal context. Studies show that students, particularly young women, prefer to apply engineering to problems with social and real-world usefulness. ${ }^{4}$

In the freshman engineering course (ENES 101), the students that completed the renewable energy solutions design project were excited by the topic. Afterwards, many individual students expressed an interest in pursuing energy engineering as a career. One of the goals of the INSPIRES module is to get younger pre-engineering students excited about engineering with real-world problems that are relevant in their own lives. Once students can establish that realworld relevance, it gives their work context and meaning, and it can help motivate them to pursue engineering as a career.

The Engineering in Health Care module has been tested in multiple school sites, and is currently in use. ${ }^{5}$ Data was collected from 78 students this past school year that used the Engineering in Health Care module to asses learning of both scientific content and understanding of the engineering design process. ${ }^{6}$

Students took an Interest and Attitude Questionnaire before and after completing the module to poll their perceptions and expectations of engineering and technology. The Questionnaire consisted of statements conveying opinions on engineering, and technology. Mean student responses appears below.

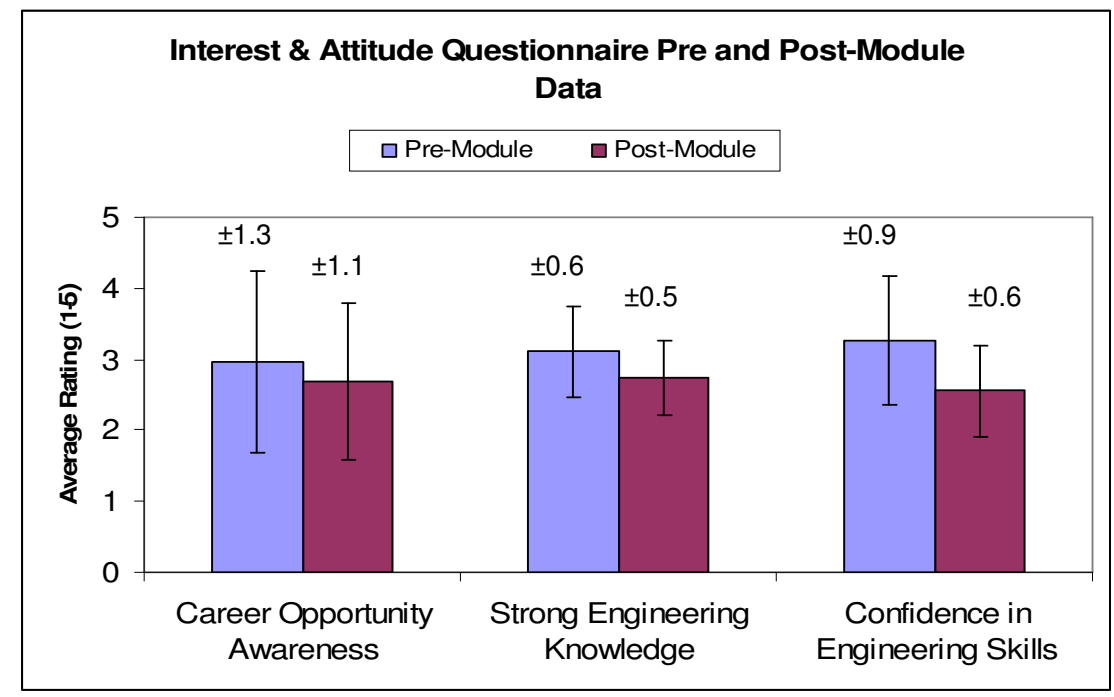

Figure 1 Average responses to the Interest \& Attitude Questionnaire from before and after completion of the module. Error bars indicate the standard deviation.

(Rating Scale: 1 = Strongly Agree, $5=$ Strongly Disagree)

Students were asked to rate their agreement with the statement on a scale of 1 to 5 . A response of 1 indicates that the student strongly agreed with the statement while a response of 5 indicates strong disagreement. Students expressed a slight increase in their awareness of career 
opportunities in engineering and technology. However, after completing a paired t-test analysis, the results show that these slight changes are not statistically significant $(p>0.05)$.

Students were also asked to indicate their current level of understanding of engineering design topics. The scale for these statements was from 1 to 5 with 5 indicating very strong and 1 indicating weak. Mean student responses showed a large improvement for many of the statements in this category. For example, in response to a consideration of the strength of their knowledge of engineering or technology, students indicated an increase in their knowledge after completing the module, which is supported by the results from the pre and post-module assessments. Students also indicated a greater increase in the strength of their confidence in their engineering skills. After completing a paired t-test analysis, the increase in engineering knowledge and confidence is statistically significant $(\mathrm{p}=0.02 ; 0.0002)$.

To supplement the data being collected from the INSPIRES module, a survey was conducted for the current students enrolled in the chemical engineering department at the University of Maryland, Baltimore County. Some of these students have taken a freshman engineering course taught by one of the authors and most completed a design project. The intention of the survey is to gain their perspective of the relevance of their design project and ask about an insights or experiences gained from having completed such a project. Some of these students have completed the energy solutions and hemodialysis design projects. According to the survey results, $58 \%$ of the chemical engineering students from UMBC decided that they wanted to pursue engineering in high school, and $48 \%$ of students decided that they wanted to pursue chemical engineering in high school. For a majority of these students, the career decision process started in high school. Early exposure to engineering as a field of study and a career helped to motivate these students to study engineering in college.

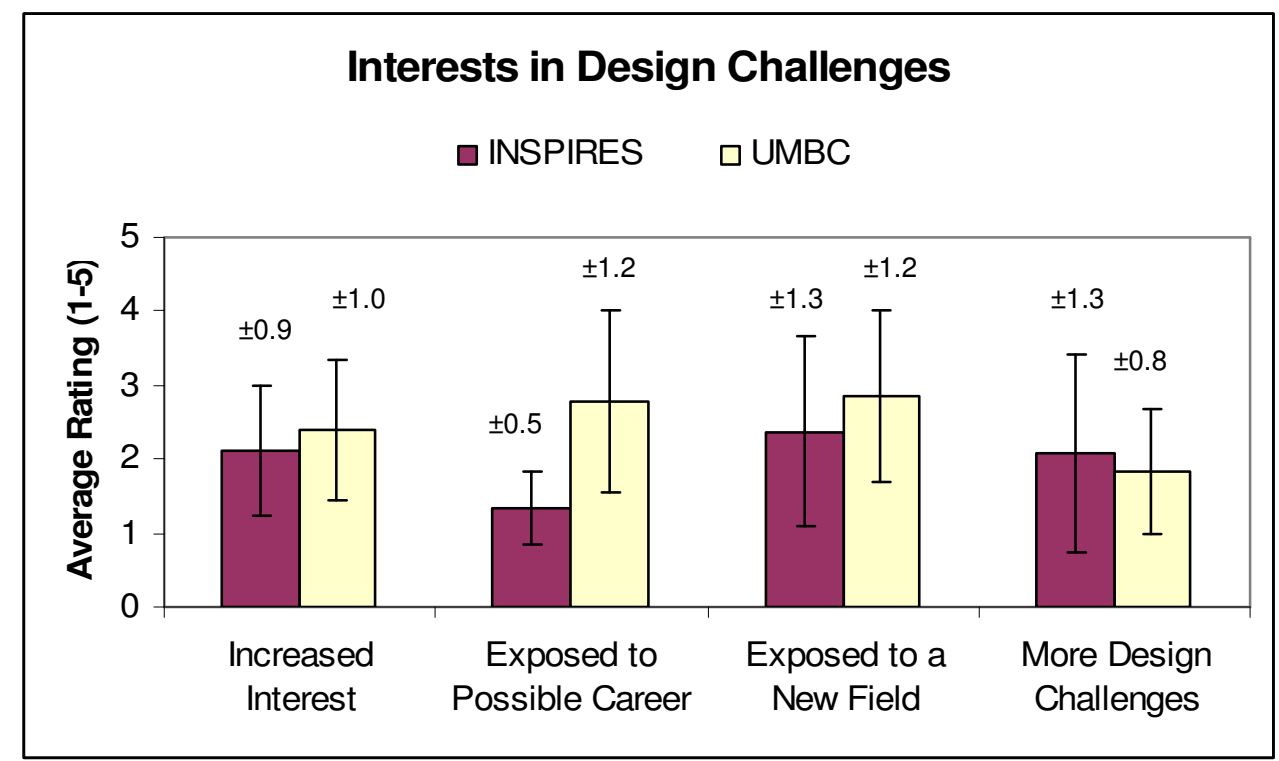

Figure 2 Averages responses to the design challenge survey questions for both INSPIRES and UMBC Chemical Engineering students. Error bars indicate the standard deviation.

(Rating Scale: 1 = Strongly Agree, $5=$ Strongly Disagree) 
In Figure 2, the average responses to four comparable survey questions are shown for both students from the INSPIRES Program as well as current UMBC chemical engineering students. The four survey items asked students to rate their agreement with four statements related to their experience with engineering design challenges. The INSPIRES students have indicated that their experiences with the curriculum have increased their interest in engineering and in completing further design challenges. The INSPIRES students also indicated that the curricula exposed them to new fields, some of which they could consider for a future career. Compared to the chemical engineering students, the INSPIRES students show a stronger response to the statements of increased interest and exposure to new fields of engineering. The chemical engineering students did not have the benefit of entire curriculum and only completed the design project. Both groups of students indicated an interest in completing further design challenges.

The survey conducted for the chemical engineering students at the University of Maryland, Baltimore County contained some other questions of interest related to their design project experience. Students were asked to indicate what first sparked their interest in engineering. Early interest in math and science course materials appear to be the most important, and interest in a particular field of research and the design challenge experience also appeared to be important factors in influencing these students to pursue engineering, as shown in Figure 3.

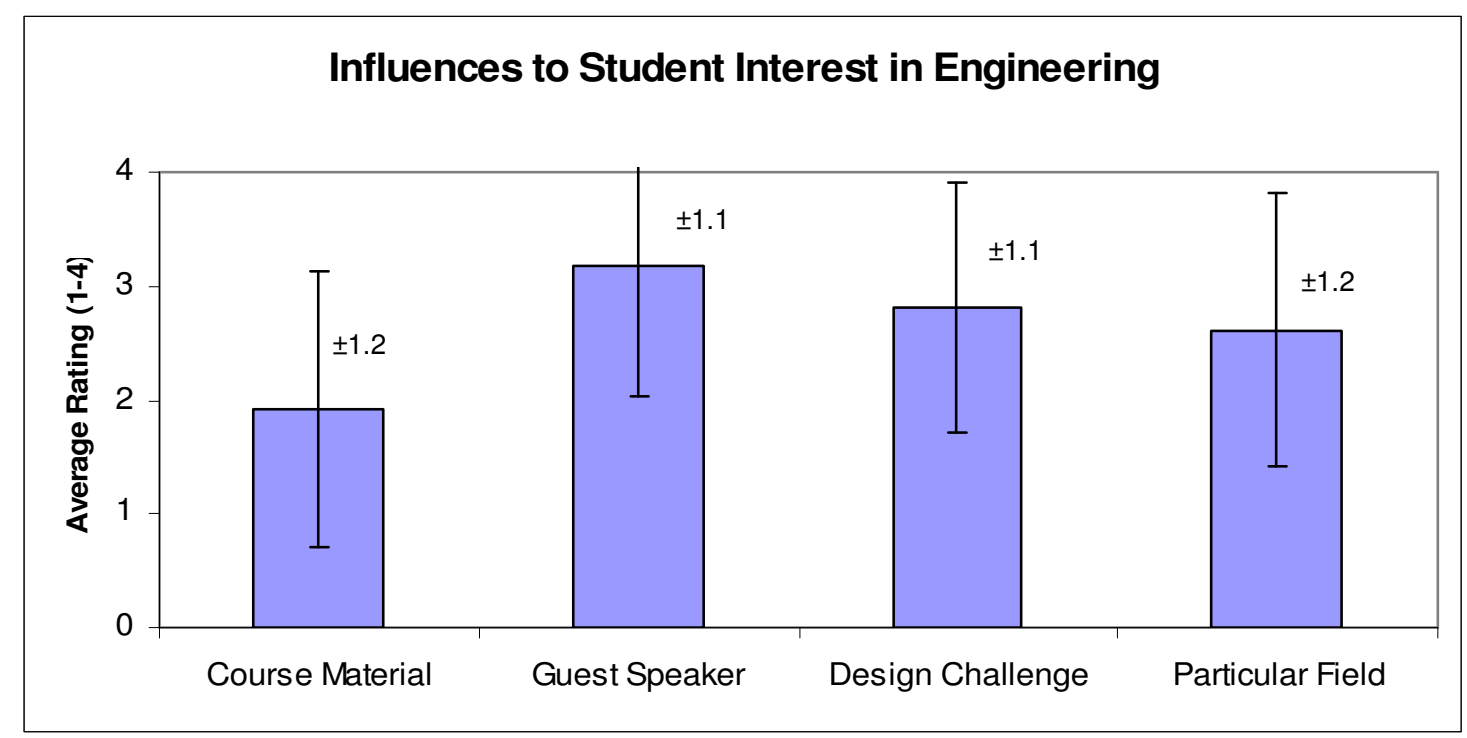

Figure 3 Averages responses to the design challenge survey questions for UMBC Chemical Engineering students. Error bars indicate the standard deviation.

(Rating Scale: 1 = Most Important, 4 = Least Important)

\section{Future Work}

While the energy solutions design challenge has been tested on both the high school preengineering and university level, the Engineering Energy Solutions module has yet to be tested in its entirety. However, testing is slated for the spring, and results will be compiled and reported in June. From the pretest and posttest scores from the freshman engineering and YESS Program students that completed just the energy design project, the results appear promising. ${ }^{2,3}$ 
Many high school teachers anticipate adopting the Engineering Energy Solutions module in the coming semester, and they are excited about the topic.

\section{Bibliographic Information:}

${ }^{1}$ Ann Leigh Speicher, "Engineering Education for a Changing World," 1994.

2 Bayles, T.M., J. Rice, G. Russ and T. Monterastelli, "High School Outreach: A Look at Renewable Energy", Paper AC 2007-1533 published in the Proceedings of the 2007 American Society for Engineering Education Annual Conference \& Exposition. Presented in the K-12 Engineering Outreach Programs Session in the K-12 \& PreCollege Engineering Division Session \#3567 at the ASEE Annual Conference, Honolulu, HI, June 27, 2007.

3 Rice, J., T.M. Bayles, G. Russ and J. Ross, "Preparing Freshmen for Future Energy Issues", Paper AC 2007-1748 published in the Proceedings of the 2007 American Society for Engineering Education Annual Conference \& Exposition. Presented in the Hands-on \& Real World Studies Session in The Freshman Programs Division Session \#2253 at the ASEE Annual Conference, Honolulu, HI, June 26, 2007.

${ }^{4}$ S.V. Rosser (ed.) Teaching the Majority: Breaking the Gender Barrier in Science, Mathematics, and Engineering (Columbia University, New York, 1995).

${ }^{5}$ Russ, G., J. Rice, C. Parker, J. Raczek, B. Jarrell, T. Bayles and J. Ross," The INSPIRES Curriculum: Engaging Future Engineers and Scientists", Paper AC 2007-2273 published in the Proceedings of the 2007 American Society for Engineering Education Annual Conference \& Exposition. Presented in the Engineering in High Schools Session in the K-12 \& Pre-College Engineering Division Session \#3667 at the ASEE Annual Conference, Honolulu, HI, June 27, 2007.

6 Ross, J.M., G. Russ, C. Parker, B. Jarrell, J. Raczek and T.M. Bayles, "New Inquiry-Based Curricula for Bioengineering Education", Paper AC 2007-2216 published in the Proceedings of the 2007 American Society for Engineering Education Annual Conference \& Exposition. Presented in the Freshman Design and Other Novel Programs Session of the Biomedical Engineering Division Session \#1309 at the ASEE Annual Conference, Honolulu, HI, June 25, 2007. 